\title{
Guidelines for Two-Year College Learning Resources Programs (Revised)
}

\author{
PART TWO
}

Approved by the ACRL Board of Directors on June 30, 1981. These guidelines supersede and replace the previous guidelines which appeared in C\&RL News, December 1972. (Part One of the guidelines appeared in $C \Downarrow R L N e w s$, January 1982, pp. 5-10).

\section{Association of College and Research Libraries \\ Association for Educational Communications and Technology}

\section{InStRuCtional System Components}

\section{A. Staff}

1. The chief administrator of the Learning Resources Program is selected on the basis of acquired competencies which relate to the purposes of the program, educational achievement, administrative ability, community and scholarly interests, professional activities, and service orientation.

The chief administrator has a management responsibility and is concerned and involved in the entire educational program of the institution as well as with the operation of the Learning Resources Program. The chief administrator is professionally knowledgeable about all types of materials and services and is capable of management of instructional development functions. Because the ultimate success of a Learning Resources Program is to a large extent dependent upon the ability of the chief administrator to perform multiple duties effectively, a comprehensive recruitment and selection process is of paramount importance.

2. The administrative (or supervisory) heads of the separate Learning Resources Units are selected on the basis of their expertise in and knowledge of the function and role of the particular Learning Resources Unit which they will manage and to which they will give leadership.

3. A well-qualified, experienced staff is available in sufficient numbers and areas of specialization to carry out adequately the purposes and objectives of the Learning Resources Program.

Depending upon the size and programs of the institution, the hours operated, the physical facilities, and the scope and nature of the services performed, the number and specializations of professional and supportive staff will vary from one institution to another.

4. All personnel are considered for employment following procedures as established by the institution.

The effectiveness of a Learning Resources Program is determined by the performance of the staff. It is essential, therefore, that all personnel-professional and support staff-be recommended for employment to the chief administrator on the advice of the Learning Resources Unit head who will be involved in the supervision of the new staff member.

5. Professional staff members should have degrees and/or experience appropriate to the position requirements.

Professional training is appropriate to assignment in the Learning Resources Program. Additional graduate study or experience in a subject field should be recognized for all personnel as appropriate to such assignments.

Professional staff members are assigned duties. They are accountable for the operational effectiveness of the Learning Resources Program as designated by the chief administrator and heads of units. They may be supervisors as well as professional consultants to the faculty and advisors to students.

6. Every professional staff member has faculty status, faculty benefits, and obligations.

Professional staff benefits include such prerogatives as tenure rights, sick leave benefits, sabbatical leaves, vacation benefits, retirement and annuity benefits, provisions for professional development, and compensation at the same level which is in effect for teaching faculty or for those at comparable levels of administration. When Learning Resources personnel work on a regular twelve-month schedule, salary adjustments will be necessary to compensate for additional service days. Where academic ranks are recognized, such are assigned to the professional staff based on the same criteria as for other faculty, and are independent of internal assignments within the Learning Resources Program.

There is the obligation of faculty status to meet all faculty and professional requirements, advanced study, research, promotion, committee assignments, membership in professional organi- 
zations, sponsorships, publication in learned journals, etc., which the institution expects of faculty members. It is expected that professional staff will abide by the institutional policy/ procedures or contractual arrangements which could include such items as staff evaluation, office hours, work assignments, and other defined working relationships.

7. Professional development is the responsibility of both the institution and the professional staff member.

Personal membership and participation in professional activities is expected of all staff members. Further graduate study should be encouraged and rewarded. The institution is expected to encourage and support professional development by providing among other benefits: consultants for staff development sessions; travel funds for regular attendance of some staff members and occasional attendance for every staff member at appropriate state or national meetings, workshops and seminars; and special arrangements for those staff members who serve as officers or committee members or participate on a state or national program.

8. Teaching assignments by Learning Resources staff members are considered dual appointments in calculating staff work loads.

When members of Learning Resources staff are assigned regular teaching responsibilities in training technicians or other classroom assignments, the hours scheduled in the Learning Resources Program are reduced by an equivalent time to allow preparation and classroom contact hours.

9. Support staff members are responsible for assisting the professional staff in providing effective services.

Responsibility for each level of support staff will be determined by the needs of the institution and the appropriate administrative structure. The number and kind of support staff needed will be determined by the size of the college and the services provided. The educational background and experience of such support staff should be appropriate to the tasks assigned.

In many instances, graduates of four-year degree programs and two-year technical programs will meet the training required; in other cases, one-year programs may be sufficient; or skills may have been learned through extensive work experience in a related position. The support staff may be supervisors as well as technical assistants or aides.

10. Student assistants are employed to supplement the work of the supportive staff.

Student assistants are important because of the variety of tasks they can perform effectively. They encourage other students to use the facilities and services, and they serve as significant means of recruitment for supportive and professional positions.

They do not, however, replace provision of adequate full-time staff, nor can their work be matched on an hour-to-hour basis with that of regular full-time employment.

\section{B. Facilities}

1. Planning of new or expanded facilities is accomplished with the participation and concurrence of the chief administrator in all details and with wide' involvement of users and staff.

The chief administrator and staff work with the architect and the administration in every decision and have prime responsibility in the functional planning of the facility. Employment of a knowledgeable media specialist or library building consultant results in a more functional and useful building operation and should be given serious consideration. In the case of specialized facilities, special technical consultants may be required. As a result of poor design, functions of many buildings fail because those persons who will be working in or using the building have not.been involved in planning. Staff, faculty, student representatives, and others who will utilize the facilities should be consulted.

2. In the design of classrooms and other college facilities where Learning Resources are to be used, Learning Resources specialists should be consulted.

The effective use of an instructional system is dependent upon the availability of a suitable environment for the use of specified Learning Resources. Frequently, architects and other college staff are not always aware of all of the technical requirements of such an environment.

3. The physical facilities devoted to Learning Resources and Learning Resources Units are planned to provide appropriate space to meet institutional and instructional objectives and should be sufficient to accommodate the present operation as well as reflect longrange planning to provide for anticipated expansion, educational mission and program and technological change.

The location and extent of space provided for development, acquisition, design, production, and use of learning resources is the responsibility of the chief administrator of Learning Resources, and should be designed to implement explicit, well-articulated program specifications developed by the Learning Resources and instructional staff of the college. Such a program should include flexible provisions for long-range development and phasing. The alteration, expansion, or consolidation of facilities also should be guided by carefully delineated program objectives which are known and understood by Learning Resources personnel, the instructional and administrative staff of the college, and the Board of Trustees. Factors to be considered when developing facilities requirements from the program specifications include projections of the student enrollment, the extent of community services, 
growth in the varieties of service, growth of materials collections, support of varying modes of instruction, staff needs, and the impact of curricular development and technological advances.

4. Facilities of Learning Resources Units should be located conveniently for use by both students and instructional staff.

Flexibility is essential to meet advances in technology and changes in instructional requirements. Service areas within the Learning Resources Unit are grouped to aid the user and to permit the staff to perform duties effectively and efficiently.

Learning Resources services for administration, acquisition, and cataloging should be centralized for more efficient operation. Planning should provide for convenient locations of facilities for storing and using equipment and materials close to the learning spaces or central to student traffic flow in which they are to be used. Where existing facilities will not permit this arrangement, an effort should be made to reduce confusion and frustration by making clear to the user the specific function of each facility.

The number of users varies in all units from peak periods when crowded conditions make service difficult to times when few students are present. Physical arrangements should make continued service with minimal staff possible during quiet times and at the same time provide for augmented service at other periods.

Services provided are dependent upon staff, whose efficiency is in turn dependent upon adequate office, workroom and storage space. The production facility should provide for consultation and demonstration space. It should be equipped to permit the demonstrating and previewing of all components of an instructional system. A staff conference room, apart from the administrative head's office, is desirable in all but the smallest institutions.

5. The physical facilities provide a wide variety of learning and study situations.

Students require various types of facilities for learning and study. Some require programmed learning equipment; others learn best by use of isolated individual study areas. In some circumstances they need to study together as a group or relax in comfortable lounge chairs. Proper arrangement and sufficient space for utilization of instructional equipment and materials should be provided for individualized instruction, browsing, and media production.

6. The physical facilities are attractive, comfortable, and designed to encourage use by students.

Attractive and well-planned areas encourage student utilization. Air conditioning and comfortable heating, proper lighting, acoustical treatment, regular custodial care, prompt maintenance of equipment, and regular and systematic repair of damages are necessary. Attention to the needs of the handicapped must be met in accordance with legal requirements.

7. Space requirements, physical arrangements, and construction provide for full utilization of specialized equipment.

Specialized facilities are necessary for certain types of equipment. For example, computer services, listening and viewing equipment, media production, and use of other types of electronic equipment require special consideration in terms of electrical connections, cables, conduits, lights, fire protection, security, and other factors which affect service.

\section{Instructional Equipment}

1. Necessary instructional equipment is available at the proper time and place to meet institutional and instructional objectives.

Centralized control of inventory and distribution of all equipment is necessary. A thorough and continual evaluation is desirable to ensure that enough of the appropriate equipment is available.

2. Classroom and Learning Resources Program use of equipment is managed in the most effective manner to minimize operational mishaps and insure effective utilization.

Assistance from Learning Resources staff is available as a regular service when needed and for the maintenance of equipment. Except for more complex equipment, the instructor and student should be responsible for the operation of the equipment.

3. Learning Resources and instructional equipment are selected and purchased on the basis of specific criteria. (See Section III.)

\section{Materials}

1. Materials are selected, acquired, designed, or produced on the basis of institutional and instructional objectives, developed by the faculty, students, and administration in cooperation with Learning Resources.

A written statement regarding acquisition and production of learning materials has such an important and pervasive effect upon the instructional program and the services of the Learning Resources Program that all segments of the academic community should be involved in its development. The statement should be readily available in an official publication.

Learning Resources Programs provide materials presenting all sides of controversial issues. The position of the American Library Association, and comparable associations, on the subject of censorship is firmly adhered to.

2. Materials may be acquired and made available from a variety of sources.

In an effort to meet the needs of the instructional process and cultural enrichment, it will be necessary to acquire materials through:

a. purchase of commercially available materials;

b. lease or rental of materials where purchase is neither possible or practical in terms of cost, 
utilization, or type;

c. loan through free loan agencies;

d. acquisition of materials as gifts;

e. design and production of materials not readily available.

3. Materials must be accessible to authorized individuals.

Although there is no uniformly accepted system to make all resources available, the materials must be properly organized and the necessary staff, facilities, and hardware provided. Highly sophisticated systems for retrieving, manipulating and displaying information might be necessary.

4. Final management decision as to the order in which materials are to be purchased or produced is the responsibility of the chief administrator or delegated subordinate.

Within the established framework of the written statement on acquisition and production, and the budgetary restraints, the final management decision and priority judgment must be the responsibility of the chief administrator and duly designated subordinates.

5. Representative works of high caliber which might arouse intellectual curiosity, counteract parochialism, help to develop critical thinking and cultural appreciation, or stimulate use of the resources for continuing education and personal development are included in the collection even though they do not presently meet direct curricular needs.

One function of higher education is to develop adult citizens intellectually capable of taking their places in a changing society. Provision of materials beyond curricular needs is essential for this goal.

6. Materials reflect ages, cultural backgrounds, intellectual levels, developmental needs, and career goals represented in the student body.

Two-year college students represent all strata of community and national life. To meet their needs, the collection must contain materials of all kinds and at all levels. Those students who require basic remedial materials, those who seek vocational and technical training or retraining, those who seek an understanding of their culture, and those who are utilizing their retirement years for personal stimulation should each find the materials which can serve their interests and solve their problems. Special care is taken to include representative materials related to the needs of minorities as well as materials reflecting divergent social, religious, or political viewpoints.

7. A broad policy is developed concerning gifts to a Learning Resources Program.

Generally, gifts are accepted only when they add strength to the collection and impose no significant limitations on housing, handling, or disposition of duplicate, damaged, or undesirable items. It is recognized that gifts frequently require more time to screen, organize, catalog, and process than new materials. Storage space and staff time requirements must be considered in accepting gift materials. In acknowledgment of gifts, attention should be called to government recognition of such contributions for tax purposes, as well as to the impropriety of any appraisal by the recipient of a donation.

8. In local reproduction of materials for instructional use, care is taken to comply with copyright regulations.

Laws restrict the copying of many items without permission. Procedures and guidelines must be established regarding reproduction of copyrighted materials and made easily accessible.

9. The reference collection includes a wide selection of significant subject and general bibliographies, authoritative lists, periodical indexes, and standard reference works in all fields of knowledge.

Every two-year college requires extensive bibliographical materials for use in locating and verifying items for purchase, rental, or borrowing, for providing for subject needs of users, and for evaluating the collection.

10. Newspapers with various geographical, political, and social points of view on national and state issues are represented in the collection.

Newspapers should reflect community, national, and worldwide points of view. Back files of several newspapers are retained in print or microform.

11. Government documents are required as significant sources of information.

Some two-year colleges which are document depositories receive government publications as a matter of course. All Learning Resources Programs should acquire regularly such publications.

12. Files of pamphlets and other ephemeral materials are maintained.

An effective and up-to-date pamphlet file is a strong resource in any college. Included are vocational and ephemeral materials developed through systematic acquisition of new materials, including subscriptions to pamphlet services and requests for free materials. References in the catalog to subjects contained in pamphlet files are desirable in providing the fullest access to the materials. Periodic weeding of the collection is essential.

Manufacturers' and publishers' catalogs and brochures which describe new materials and equipment are needed to supplement published lists and to provide up-to-date information.

13. A collection of recorded and other materials should be available for individual use as well as for meeting instructional needs.

14. Policy or procedures for the conservation of materials, deletion, and weeding the collection of obsolete materials should be developed as part of an ongoing procedure.

The materials in the collection should be examined regularly to eliminate obsolete items, un- 
necessary duplicates, and worn-out materials. Procedures regarding deletion need to be explicit for weeding and disposing of such materials. Prompt attention must be given to damaged materials so that repairs and replacement (including rebinding of printed materials or replacement of portions of projected or recorded materials) are handled systematically, along with prompt action to replace important items, including those discovered to be missing.

15. The Learning Resources Unit functions as an archive for historical information and documents concerning the college itself.

An effort should be made to locate, organize, and house institutional archives to the extent defined by the administration.

\section{SERVICES}

A. Users of Learning Resources have the right to expect:

1. That facilities, materials, and services are available and accessible to meet demonstrated instructional needs for their use regardless of location;

2. That an atmosphere be provided which allows sensitive and responsive attention to their requirements;

3. That professional staff be readily available for interpretation of materials and services and for consultation on instructional development;

4. That physical facilities be properly maintained to make use comfortable and orderly;

5. That requests for scheduling, circulation, distribution, and utilization of materials and related equipment be handled expeditiously;

6. That acquisition, production, and organization of materials meet educational, cultural, and personal needs.
7. If an institution is conducting classes in offcampus locations, careful planning and funding must be provided to ensure that equal services are available to those programs.

\section{Interagency Cooperative ACtivities}

A. Cooperative arrangements for sharing of resources are developed with other institutions and agencies in the community, region, state, and nation.

To provide the best possible service to the students and faculty in the two-year college, close relationships with other local institutions and agencies and with institutions of higher education in the area are essential. Through consortia, media cooperatives, and loan arrangements, institutions can share resources. The college may need to make arrangements so that its students may use the area facilities and resources. When an undue burden is placed on a neighboring institution, financial subsidy may be appropriate.

B. The institution is willing to consider participation in cooperative projects, such as shared cataloging, computer use, and other services which may be mutually beneficial to all participants.

By cooperative planning much expense and wasteful duplication can be avoided in the community and region. Learning Resources personnel and institutional administrators need to be alert to cooperative activities of all kinds and to be willing to explore the possibilities of participation for their own institution.

C. Responsibility for the collection and preservation of community history and for the accumulation of other local and statistical data is shared with other institutions and is coordinated with them.

\section{Proposed Bylaws of the Law and Political Science Section}

Editor's Note: The following proposed bylaws will be voted on by LPSS members at the 1982 ALA Annual Conference in Philadelphia.

\section{Article I. Name}

The name of this organization is the Law and Political Science Section of the Association of College and Research Libraries.

\section{Article II. Object}

The Section shall represent librarians in the field of law and political science. It will act for ACRL in cooperation with other professional groups in regard to those aspects of library service that require special knowledge of law and political science.

\section{Article III. Membership}

Any member of ACRL may elect membership in the Section. Every personal member has the right to vote and is eligible to hold office.

\section{Article IV. Meetings}

The Section shall hold an annual meeting at the time and place of the Annual Conference of the American Library Association. Other meet- 